\title{
Perceptions of Learners of a Learning Management System to Support Teaching and Learning Using the Diffusion of Innovation Theory
}

\author{
Dr Desmond W. Govender \\ University of KwaZulu-Natal, Edgewood Campus, South Africa \\ Email: govenderd50@ukzn.ac.za \\ Prof Manilall Dhurup \\ Vaal University of Technology, Private Bag X021, \\ Vanderbijlpark, 1900, Gauteng, South Africa \\ Email: royd@vut.ac.za \\ Mrs Y. Mudaly \\ UKZN (Student), Edgewood Campus, South Africa
}

\section{Doi:10.5901/mjss.2014.v5n8p377}

\section{Abstract}

\begin{abstract}
Online learning is one of the ways in which the Internet can be used as a learning tool which can provide support to educators in a classroom. The purpose of this study was to investigate the use of a Learning Management System LMS to support teaching and learning in a Grade 10 Information Technology (IT) class. The emphasis was on the attitudes and experiences of learners in relation to implementation of the LMS as a teaching and learning tool in the classroom. This study employed a mixed-methods approach (a combination of quantitative and qualitative approaches). The quantitative approach included an attitudinal survey in the form of a questionnaire which used Likert scales to assess responses to various statements. The qualitative approach concerned itself with production of in-depth data. Focus group interviews were conducted with Grade 10 IT learners. These instruments generated data that were used to answer the main research question: What are learners' experiences and attitudes when using a LMS? In terms of analysis of the data thematic analysis was used, with texts representing qualitative data and tables and statistics representing quantitative data. In order to discuss the findings the characteristics (attributes) of an innovation, as explained in the Diffusion of Innovations Theory were used. The research findings indicated that the learners had a positive attitude towards the use of the LMS to support teaching and learning and they were keen for it to be implemented in other subjects.
\end{abstract}

Keywords: Learning management system, technology adoption, diffusion of innovation, teaching and learning.

\section{Introduction}

The potential of the Internet as a learning tool has emerged as a result of its increased development and its use as a means of communication in various academic institutions. Online learning is one of the ways in which the Internet can be used as a learning tool which can provide support to educators in a classroom. The tools which support online learning cover a wide range of different applications, such as discussion forums, chat and file sharing. These tools can be used to support different activities in the learning process, such as content delivery and encouraging collaboration between the various people that participate. It is possible to link these different tools into a single system such as a learning management system (LMS). WebCT, BlackBoard and Moodle are examples of such LMSs. It is within the context of this background knowledge that the study on hand investigated the use of a LMS.

LMS is a server-based software program that interfaces with a database containing information about users, courses and content. A LMS provides a place for learning and teaching to occur within an integrated environment (Ullman \& Rabinowitz, 2004). These systems allow educational institutions to offer a larger number of full online or blended/hybrid (partly online and partly face-to-face) courses. Face-to-face courses that use a LMS to supplement activities are often referred to as web-enhanced courses (Schmidt, 2002). LMSs are known in the literature by several different names, including course management system, virtual learning environments and e-learning courseware (Gibbons, 2005).

The focus of this study was to investigate the use of an LMS in the teaching and learning of a Grade 10 Information Technology (IT) class, with emphasis on the attitudes and experiences of learners in relation to implementation of the LMS as a teaching and learning tool in the classroom. 


\section{Theoretical Framework and Learning Management Systems (LMS)}

The diffusion of innovation (DOI) model (Rogers, 2003) constituted the theoretical framework for this study. DOI theory is commonly used in information systems. DOI seeks to explain the process and factors that influence the adoption of new innovations (Rogers, 2003). Rogers (2003:5) defines diffusion as "a process in which an innovation is communicated through certain channels over time amongst members of a social system." Rogers defines several intrinsic characteristics of innovations that influence an individual's decision to adopt or reject an innovation. According to DOI, the likelihood that an innovation will be adopted depends partly on its attributes. The following five attributes are considered in DOI: relative advantage, compatibility, complexity, trialability and observability.

- Relative advantage is the degree to which an innovation is perceived as better than the idea it supersedes. The degree of relative advantage may be measured in economic terms; social prestige, convenience, and satisfaction. It does not matter much if an innovation has a great deal of advantage, what does matter is whether an individual perceives the innovation as advantageous. The greater the perceived relative advantage of an innovation, the more rapid its rate of adoption will be.

- Compatibility is the degree to which an innovation is perceived as being consistent with the existing values, past experiences, and needs of potential adopters. An idea that is incompatible with the values and norms of a social system will not be adopted as rapidly as an innovation that is compatible. Adoption of an incompatible innovation often requires prior adoption of a new value system which is a relatively slow process.

- Complexity is the degree to which an innovation is perceived as difficult to understand and use. Some innovations are readily understood by most members of a social system; others are more complicated and will be adopted more slowly. New ideas that are simpler to understand are adopted more rapidly than those that require the adopter to develop new skill and understandings.

- Trialability is the degree to which an innovation may be experimented with on a limited basis. New ideas that can be tried on the instalment plan will generally be adopted more quickly than innovations that are not divisible. An innovation that is trialable represents less uncertainty to the individual who is considering it for adoption, who can learn by doing.

- Observability is the degree to which the results of an innovation are visible to others. The easier it is for individuals to see the results of an innovation, the more likely they are to adopt it. Such visibility stimulates peer discussion of a new idea.

Innovations that are perceived as having all these elements will be adopted more rapidly than others.It is within the boundaries of this theoretical framework that the research question was answered.

\section{Purpose of the Study}

The purpose of this study was to investigate the use of a LMS to support teaching and learning in a Grade 10 Information Technology (IT) class.

\section{Research Design and Methodology}

This study employed a mixed-method approach, using both qualitative and quantitative methods. Qualitative research involves collecting textual or verbal data (data which cannot be counted), while qualitative methods basically involve observation of people followed by careful description and analysis (Boeree, 2007). Quantitative research, on the other hand, is more highly defined and closely related to research in the physical sciences, and involves collecting numerical data which can be counted (Mouton \& Marais, 1994). Quantitative data collection methods make use of a limited range of predetermined responses whereby the experiences and perceptions of people can be measured. The quantitative approach was used to analyse the data from the questionnaire, while the interviews used the qualitative approach.

\subsection{Context and sampling}

The participants in this study were Grade 10 IT learners from a Secondary School in KwaZulu-Natal (South Africa). There were 29 learners in the class, but only 28 participated in this research. 


\subsection{Methods of data collection}

In order to obtain data that would further the aims of the study and to strengthen this study it was decided that it was necessary to use more than one data collection method. The observation, interview and questionnaire enabled the researcher to obtain data that were used to provide answers to the research question: the researcher observed the learners' interaction with the LMS, gauged the attitudes of learners towards using a LMS through the questionnaire, and gauged learners' perceptions and experiences of using the LMS through the interview.

\subsection{Data analysis and interpretation}

The data from the questionnaire were captured on a spreadsheet in terms of actual numbers, which facilitated statistical representation of the data in percentages and graphs. The DOI constructs were each operationalised in five statements/questions. Analysis of data encompasses breaking up complex data into manageable themes, patterns, trends and relationships (Mouton, 2001). Analysing what the respondents have said in an interview requires the researcher to relive the interview and to tie up the responses with the underlying theories, while looking for evidence in support of the theories and that which contradicts it (Gaskell, 2000). This part of the analysis began with producing the transcript of the group interviews. Once the transcripts were done, the researcher looked for themes and categories that were associated with the theoretical framework, keeping the research question in mind. The analysis included data from the questionnaire and the interview.

\subsection{Ensuring trustworthiness of the study}

Application of a multi-method approach allowed for a comparison of data - referred to as triangulation (Krefting, 1991). According to Denzin and Lincoln (2003) triangulation is a means of ensuring concurrent validity and prevents personal bias. Validity refers to the appropriateness of the conclusions claimed from the analysis of the collected data (McMillan \& Wergin, 2002). This has to do with whether the research methods, approaches and techniques used were appropriate to the study conducted. To ensure credibility in this study, the researcher interviewed (using a voice recorder) the participants with an intention to gain insight into their understandings and experiences about the learning benefits and challenges they were facing with integration of a LMS in teaching and learning. The interviews were then transcribed. Learners had an opportunity to read the transcripts to ascertain whether they were a true reflection of their responses. Data were also collected from observation of lessons using the LMS and a questionnaire. The collection of data from differences sources adds to the strength of the validity, reliability and trustworthiness of the study.

\subsection{Ethical issues}

According to McMillan and Schumacher (2006), ethical issues refer to all the precautions, steps and efforts that researchers carefully put into practice to protect the research participants while interacting with them for data production. Bell (2005) argues for the establishment of ethics committees which can ensure that no badly designed or harmful research is permitted. A credible research design involves the appropriate selection of participants and effective research strategies, all of which adhere to principles of research ethics. During the planning and implementation of this research due consideration was given to ethical issues in using learners as part of the data collection method. All ethical procedures were followed, which included obtaining ethical clearance from the university and the Department of Education as well as obtaining signed consent letters from the parents of the learners and the learners themselves.

\section{Results and Discussion}

According to Rogers (1995), people's attitudes towards a new technology are a key element in its diffusion. The characteristics (attributes) of an innovation influence an individual's decision to adopt or reject an innovation (Rogers, 1995). Rogers (2003) stated that five attributes impact on a person's choice to adopt an innovation: relative advantage, compatibility, trialability, observability, and complexity. Rogers termed these the "perceived attributes" of innovations. The questionnaire was used to operationalise Rogers' five factor theory on innovation adoption.

Likert scales were used to determine learners' attitudes towards these attributes. Learning-related questions, interactive questions and technology-related questions were employed to assess the impact and context of adoption of the LMS by learners. All of the questions were answered on a Likert scale. Data from the questionnaire were captured on 
Microsoft Excel. The questionnaire has been summarised with learners' responses under the following headings: 'Strongly disagree', 'Disagree', 'Neutral', 'Agree', and 'Strongly agree'. In the discussion percentages are used to indicate learner responses.

\subsection{Relative advantage of using a LMS}

Rogers (2003:229) defines relative advantage as the "degree to which an innovation is perceived as being better than the idea it supersedes". To measure relative advantage the researcher used five statements to determine whether or not the LMS is a useful innovation (Table 1). According to Rogers (2003), the higher the perceived relative advantage, the more likely it is that the innovation will be adopted. Table 1 provides an exposè of learners' responses in percentages for the relative advantage dimension.

Table 1: Relative advantage of the LMS

\begin{tabular}{|c|c|c|c|c|c|}
\hline Relative advantage & $\begin{array}{l}\text { Strongly } \\
\text { disagree }\end{array}$ & Disagree & Neutral & Agree & $\begin{array}{c}\text { Strongly } \\
\text { agree }\end{array}$ \\
\hline Using the LMS saves time & - & - & 7 & 32 & 61 \\
\hline The LMS is a positive innovation & - & - & 4 & 35 & 61 \\
\hline The LMS makes learning more meaningful & - & - & 21 & 32 & 47 \\
\hline $\begin{array}{l}\text { The LMS makes it more convenient to communicate with } \\
\text { my teacher and friends }\end{array}$ & 4 & - & 7 & 25 & 64 \\
\hline The LMS is a fast and efficient way of getting information & - & - & 7 & 43 & 50 \\
\hline
\end{tabular}

Table 1 indicates that the majority of the learners agreed that the LMS is useful; $96 \%$ agreed with the statement that the LMS is a useful innovation in that it saves time, and $61 \%$ of these strongly agreed. The possible reason for the majority of the learners' responses about the LMS saves time and is positive, fast and efficient is due to the fact that once they were logged into the system, they were able to access the content without experiencing any difficulty. The lesson content, whether a PowerPoint presentation or browsing the Internet for information, presented very few problems. This can be corroborated from the statements made by learners during their interviews when they were asked the question "Did you experience any problems when using the LMS?" These were some of the responses:

\footnotetext{
"No I did not have any problems";

"No problems";

"No not the LMS. It was just the server".
}

The learners' emphatic and unequivocal responses to the question indicate their strong support for the LMS. In this context it can be surmised that the LMS is a progressive innovation.

From the observation, it was noted that the learners managed to access the relevant tools rapidly and efficiently. Whilst $79 \%$ agreed that the LMS contributed meaningfully to their learning, $21 \%$ of learners did not feel strongly enough that the LMS has contributed to their learning. Since not all learners are technology savvy and this was their first experience using a LMS to learn, it ought to be expected that there would be a percentage of learners who were unsure about how the LMS contributed to their learning. Also, the concept "meaningful learning" may be interpreted differently by different learners, and therefore many learners preferred to remain neutral. It is also important to note though that they did not disagree.

Previous studies also affirm these findings. Murphy and Lindner (2001) administered a survey to 111 students in an undergraduate course on technological change which used WebCT through the semester. Students were asked questions about their perceptions on the use of WebCT. Overall, $70 \%$ of the students agreed that WebCT had tangibly contributed to their success in the course. Eighty-nine per cent of the students had a positive perception of the use of WebCT. The findings indicate that there was a positive response to all five statements for relative advantage. Analysis of data from the questionnaire indicates that the LMS is a useful innovation and that Rogers' relative advantage is favoured as one of the characteristics of the innovation.

\subsection{Compatibility of the LMS}

Rogers (2003:15) defines compatibility as the "degree to which an innovation is perceived as consistent with the existing 
values, past experiences and needs of potential adopters". Furthermore, Rogers (2003) stated that if the innovation is perceived as an extreme change, then it will not be compatible with past experiences and is less likely to be adopted. This second component of Rogers' model was assessed by whether the LMS would require the participants to change their work habits. Again the researcher used five statements to determine compatibility of the LMS with the participants, and Table 2 outlines learners' responses to them in percentages.

Table 2: Compatibility of the LMS

\begin{tabular}{|c|c|c|c|c|c|}
\hline Compatibility & $\begin{array}{l}\text { Strongly } \\
\text { disagree }\end{array}$ & Disagree & Neutral & Agree & $\begin{array}{c}\text { Strongly } \\
\text { agree }\end{array}$ \\
\hline I look forward to receiving emails from my friend on the LMS & - & 4 & 17 & 29 & 50 \\
\hline I am eager to respond to the discussion group on the LMS & - & 4 & 35 & 25 & 36 \\
\hline The LMS is compatible with the way I like to work & & 11 & 10 & 25 & 54 \\
\hline Using the LMS would require me to change my study habits & 4 & 18 & 10 & 29 & 39 \\
\hline $\begin{array}{l}\text { Using the LMS increases my interaction with the subject } \\
\text { content }\end{array}$ & - & 4 & 11 & 21 & 64 \\
\hline
\end{tabular}

The results reveal the LMS is a compatible innovation since the majority of the learners responded positively to all five conceptual measures of compatibility. As can be determined from table 3, 85\% (64\% strongly agree, $21 \%$ agree) of the learners agreed that by using the LMS, their interaction with the subject content increased. Learners interacted with the subject content on a one-to-one basis. Each learner worked independently and progressed from one section to the next at their own pace, thus increasing their interaction with the content and at the same time making learning more meaningful. The statement "using the PowerPoint from the LMS helped me to learn better instead of sitting and reading a textbook" made by learners during the interview process supports the fact that learners were engaged in meaningful learning.

Every day many learners spend numerous hours immersed in popular technologies such as Internet and email. It is not surprising that Internet access with email facility has taken up space in many educational institutions and is fast becoming a reality in and out of the classroom. Seventy-nine per cent of the learners looked forward to receiving emails on the LMS, and the same percentage found the LMS compatible with the way they like to work. It therefore seems that the new generation of learners have witnessed the impact of having developed in the digital era; digital technologies are a fully integrated aspect of their lives (Green \& Hannon, 2007). Many learners own mobile devices with Internet connectivity and email access, and as a result can identify with LMS technology. This could be a possible reason why they found the LMS so compatible. Sending and receiving emails whilst in a class via the LMS was a first for this group of learners, and therefore they found it exciting. Another contributing factor could be that these learners study IT and are exposed to technology (Internet access) and are familiar with use of the computer as compared to a learner who does not study IT.

This group of learners was previously not exposed to a LMS, and since this is a new technology to the approach of teaching and learning, $68 \%$ (29\% agree, 39\% strongly agree) of learners agreed that use of the LMS would change their study habits. It was evident though their facial expressions and informal conversations that learners were impressed that they had access to up-to-date and current information at the click of a button. Many learners felt that traditional use of a textbook can now be replaced by use of a LMS. As one of the interviewees stated "the information was up to date rather than using textbooks which were printed years ago with outdated equipment".

Table 2 shows that $35 \%$ of the learners were neutral regarding the discussion group on the LMS. It is possible that in the initial stages that these learners were afraid to express their ideas since it was their first experience. There were learners with diverse learning abilities in the class, not all comfortable with expressing their views for the entire group to read. For some of the learners the discussion group (which many referred to as a chat group) would be an alternative for them to say what they wanted and not be afraid. However, most of the learners (25\% agree, $36 \%$ strongly agree) indicated that they were eager to participate in the discussion group. These learners were eager to write something, even if was not related to the topic of discussion, and from my observation this was an opportunity to write what they wanted without being interrupted. Waiting and replying to responses from the other learners prompted more learners to participate in the discussion. The learners were totally surprised that the educator also participated in the online discussion in class. When asked which specific tool they found the most beneficial when using the LMS, learners responded as follows:

"The group discussion everybody contributed ... had a friend to contact"; "It's online and you can see what is happening"; 
"The chat was interesting";

"We can contribute to the discussion and ask questions to the teacher which she answered".

Observation revealed that the learners were notably excited (evident in the comments they made amongst each other) about the use of the LMS. At the end of each lesson, as the learners left the class, they would casually ask questions like: "Why did we not use this sooner" and "Why don't we use this in all subjects?" This confirmed that there was a positive attitude toward the LMS.

The overall mean for compatibility is $74.4 \%$ (agree and strongly agree), indicating that this characteristic has been favoured positively, and the LMS is compatible with the learners' needs. A positive response also indicates that there will be an increase in the adoption rate of the LMS, with more learners wanting to adopt it.

\subsection{Trialability of the LMS}

Rogers (2003:16) defined trialability as "the degree to which an innovation may be experimented with on a limited basis". This may include trying out parts of a program or having the opportunity to watch others using a new program. Rogers (2003) added that trialability is positively related to the likelihood of adoption. The statements that tested trialability are seen in Table 3, which gives the learners' responses to the statements in percentages.

Table 3: Trialability of the LMS

\begin{tabular}{|c|c|c|c|c|c|}
\hline Trialability & $\begin{array}{l}\text { Strongly } \\
\text { disagree }\end{array}$ & Disagree & Neutral & Agree & \begin{tabular}{|c}
$\begin{array}{c}\text { Strongly } \\
\text { agree }\end{array}$ \\
\end{tabular} \\
\hline $\begin{array}{l}\text { I am not worried about making mistakes by clicking on the wrong item } \\
\text { when I use the LMS }\end{array}$ & 11 & 18 & 29 & 21 & 21 \\
\hline I can practice using the LMS at a comfortable pace & - & 4 & 6 & 11 & 79 \\
\hline The LMS can be easily tried out & - & - & 25 & 32 & 43 \\
\hline I am not hesitant to use the LMS even though I make mistakes & - & & 11 & 32 & 57 \\
\hline The LMS does not intimidate me & - & 4 & 18 & 32 & 46 \\
\hline
\end{tabular}

It seems that the majority of the learners were comfortable working and experimenting with the LMS on a trial basis. From Table 3, it can be seen that $89 \%$ (32\% agreed, $57 \%$ strongly agreed) of them agreed that they can use the LMS at a comfortable pace, and that even though they made mistakes they were not hesitant to continue to use the LMS. Learners were not intimidated by the LMS because of their exposure to digital technology in and out of school. As mentioned earlier, this group of learners is advantaged because they study IT and as a result are exposed to a variety of programs and user interfaces. Responses from the interview also indicated that learners managed to work comfortably with the LMS. When asked what challenges they faced when using the LMS in the classroom, one learner said "No there were no challenges for me, everything went smoothly and I was able to access everything", and another responded "I understood what you said so there were no challenges for me". Similarly, another felt that "there's no challenges at all because it was simply written and it was like straightforward stuff where you can just click and go to the next slide so you know what you are going through".

One of the few challenges faced was connectivity. Since many learners were using the LMS simultaneously, the server became sluggish and the Internet kept disconnecting. Initially many learners indicated that it was too timeconsuming to get logged into the LMS, and as a result they became frustrated. This was purely a technical problem. The server hosting the schools website and the Internet bandwidth were both slow. After some changes were made this was rectified, and thereafter very few problems were experienced with regard to gaining access to the LMS. Few learners experienced problems with their username and passwords. After this problem was overcome, all learners were able to access the LMS without any difficulty. This was validated by the following responses from learners during the interview process when asked what challenges they experienced:

"Nothing with the LMS itself ... but connectivity";

"I think it will only be speed of the modem which is sometimes slow when there are too many learners using LMS ... the speed slow";

"When using the LMS I had no problems just that the Internet server kept disconnecting";

"... sometimes I couldn't log into my account because the password was incorrect and as a result sometimes the time wasn't enough to complete tasks". 
Few learners (29\%) were worried about making mistakes by clicking on the wrong item. Learners who were unsure either asked their friends next to them or the educator before proceeding. The observation process provided evidence of this. After a while they adapted to the interface of the LMS and progressed unhindered using it at their own pace.

It seems that the characteristic of trialability has been positively received by the learners. Trialability positively correlated to the rate of adoption, thus contributing to increased use and possible adoption of the LMS.

\subsection{Observability of the LMS}

Rogers (2003:6) defined observability as: "the degree to which the results of an innovation are visible to others". Table 4 reflects the responses of learners to the statements used to test the observability of the LMS, in percentages. According to Rogers (2003), if the observed effects are perceived to be small or non-existent, then the likelihood of adoption is reduced.

Table 4: Observability of the LMS

\begin{tabular}{|l|c|c|c|c|c|}
\hline \multicolumn{1}{|c|}{ Observability } & Strongly disagree & Disagree & Neutral & Agree & Strongly agree \\
\hline I have seen other subjects in my school make use of a LMS & 57 & 18 & 14 & 4 & 7 \\
\hline I have seen other schools make use of a LMS & 61 & 32 & 7 & - & - \\
\hline I have seen the use of a LMS on television & 65 & 21 & 14 & - & - \\
\hline I am aware of a LMS being used in a university & 50 & 25 & 7 & - & 18 \\
\hline I have not seen a LMS before & 50 & 7 & 4 & 14 & 25 \\
\hline
\end{tabular}

The summary of responses as tabulated in Table 4 indicates that most learners in general had not seen or used a LMS previously. Table 4 shows that none of the learners had heard of other schools that made use of a LMS or seen one used on television. Seventy-five per cent of the learners were not aware of use of a LMS at a university. This may be substantiated by responses from the interview process. Of the 28 learners interviewed, 25 responded with an unequivocal "No!" when asked if they had previously used a LMS. A small number (only 3 learners) indicated that they were only exposed to a LMS in the IT class when it was first introduced: "no not until we started the programme at our school in our IT class"; "no only in our IT class"; and "no only when you taught it to us". It can therefore be concluded that all learners interviewed had no previous experience with a LMS, indicating that the LMS is relatively new to the teaching and learning process.

Eighteen per cent indicated that they had seen the use of am LMS at a university. These learners may have family members who are currently using am LMS to study or to lecture. Eleven per cent of the learners indicated that they had seen other subjects in their school use a LMS. This is possible because the school currently has six e-learning centres which make use of CMSs to teach mathematics, physical science and life sciences. These learners, however, do not have hands-on experience with this program; the teacher uses the CMS to project the content via a data projector.

The statement "I have not seen a LMS before" was written in the negative, and only 39\% of the learners agreed with this. This implies that the other $61 \%$ disagreed with the statement, meaning that they had seen a LMS before (4\% were neutral). This is, however, not in keeping with the previous four statements. Learners may have misinterpreted this statement, because it is a contradiction to when the majority emphatically said they were not aware of the use of a LMS at school, on television or at a university. Since this is only one of the five statements that showed a contradiction, the observability construct is still positively received.

This study is conducted on the basis that the learners have not used a LMS previously, and it stands to reason that a fair percentage will indicate that they have not seen a LMS in use. Table 4 shows that the observability characteristic clearly indicates that a LMS is a relatively new domain and learners have not been adequately exposed to a LMS since more traditional means of teaching and learning have taken precedence, despite the rapid popularity in and growth of technology. According to Rogers (2003), if observability is positively received then the rate of adoption is greater. Even though majority of the learners had not previously seen a LMS in use, they were still positive to its adoption. The reason for this may be because they were eager to have a new technology introduced into the classroom - more especially a technology that they can identify with because of email, chat, and Internet access. Traditionally these tools were not allowed in the classroom, and now the learners are using them to supplement their learning. Learners in the digital era are so up-to-date with new technological devices (such as cell phones and iPads) that even though they have not observed a LMS in use, they experienced minimal problems regarding its integration into the classroom. 


\title{
5.5 Complexity of the LMS
}

Rogers (2003:242) explains complexity as the "degree to which an innovation is perceived as relatively difficult to understand and use". Innovations that are perceived as complex are less likely to be adopted. The five measures used to examine complexity of the use of the LMS can be seen in Table 5, which indicates the learners' responses in percentages.

Table 5: Complexity of the LMS

\begin{tabular}{|c|c|c|c|c|c|}
\hline Complexity & $\begin{array}{l}\text { Strongly } \\
\text { disagree }\end{array}$ & Disagree & Neutral & Agree & $\begin{array}{c}\text { Strongly } \\
\text { agree }\end{array}$ \\
\hline Interacting with the LMS is frustrating & 68 & 15 & 17 & - & - \\
\hline The LMS is user-friendly & - & - & 7 & 25 & 68 \\
\hline The LMS is too complex for me & 79 & 21 & & & - \\
\hline I am confident in my ability to use the LMS & - & - & 7 & 29 & 64 \\
\hline When using the LMS I find it easy to navigate from one screen to another & - & 4 & 17 & 29 & 50 \\
\hline
\end{tabular}

Complexity was tested with a mixture of positive and negative statements. The statistics show a balance between the positive and negative responses, in favour of showing that the LMS is not a difficult tool to use. None of the learners agreed that the LMS was too complex (21\% disagreed, $79 \%$ strongly disagreed). In keeping with this, 93\% (29\% agreed, $64 \%$ strongly agreed) indicated that they were confident in using the LMS. Observation showed that this was a true reflection, because the overwhelming majority of learners were able to navigate through the LMS without any difficulty. They were able log in with their user name and password and then access the content without needing any assistance from their peer or the educator.

Five learners (17\%) indicated that their interaction with the LMS was frustrating. These learners included those who experienced technical problems as mentioned previously, such as loss of Internet access and problems with logging into the LMS or computer-related problems. Whilst navigating through the content, learners sometimes had to access the Internet, and because there was a drop in signal, learners showed some signs of anxiety. During the group interview process learners were asked to discuss what problems or challenges they had experienced when using LMS. These were some of the responses:

\author{
"No did not have any problems"; \\ "The connectivity also gave us a problem but we eventually connected"; \\ "No besides the Internet getting cut off"; \\ "Nothing with the LMS itself ... but connectivity".
}

These responses clearly support the figures in Table 5. The complexity of a technology affects how well that technology diffuses into a social network system, because if the technology is easy to use more people are likely to adopt it. Findings from this study support this statement, and Table 5 shows that the LMS was quite easy to use and thus likely to be widely adopted. The complexity construct showed positive results from the majority of the learners.

The findings thus far have shown how the constructs in the DOI model fared positively, and thus can be used to predict the diffusion of a LMS. This study analysed issues surrounding adoption of a LMS using DOI to test its adoption amongst Grade 10 secondary school learners. Five major constructs (relative advantage, compatibility, trialability, observability and complexity) were used to test impact on attitudes and trust regarding use of a LMS and to determine how attitude would impact on intention to use it. From the results it is noted that the relative advantage of using a LMS, how compatible it was with the lifestyle of the learners, whether the LMS could be tested before consistent use, how much had been registered about the LMS by the learners, and how hard it was to use were issues that influenced users' attitude towards their intention to use it. Since all of these constructs have an impact on attitude, it follows that the LMS is in keeping with the learners' lifestyle and would assist in adoption of a LMS amongst learners.

\section{Limitations and Implications for Further Research}

A limitation of the study was the sample size had only one class $(n=28)$ which was chosen for the study. The student sample may not necessarily reflect the pattern of perceptions across the spectrum of the population, especially among non-IT classes. Hence, the study limits generalizability to the entire population of student groups. The research could be 
extended in examining the perceptions of learners of a learning management system through a comparison of different schools types such as private and public schools. The study was based and adapted from the diffusion on innovation model (DOI) of Rogers (2003). Further research could be undertaken using other models such as the unified theory of acceptance and use of technology (UTAUT) developed by Venkatesh and Davis (2000); Venkatesh, Morris, Davis and Davis (2003) which extends the technology acceptance model (TAM) taking into account several constructs that have significant influence on behavioural intention and ultimately usage of technologies or George Siemens' theory of connectivism a "learning theory for the digital age" (Siemans, 2004:1).

The study opens up avenues for further research regarding learning management systems and perhaps a longitudinal study within a certain cohort of students in order to track their academic success and achievements of a longer period.

\section{Conclusion}

The introduction of the use of LMS in our schools to support teaching and learning will not only create new possibilities for our learners to engage in new ways of learning, but also provide them with digital media (which have taken over the information society). Exposure to the latest digital technology such as the LMS has dramatically changed the learning and teaching process, and expanded new learning opportunities and access to educational resources beyond those of the traditional classroom. Further research must be conducted by academics to investigate both learner and teacher experiences when using a LMS in the classroom. It is evident that the LMS is a useful innovation and a supportive tool in teaching and learning.

\section{Acknowledgements}

The data for this study was collected by Mrs R. Mudaly a master's student of Dr DW Govender.

\section{References}

Bell, J. (2005). Doing your Research Project: A guide for first-time Researchers in Education, Health and Social Science (Ed.). London: Open University Press

Boeree, G.C. (2007). Personality Theories: An Introduction. Retrieved May 10, 2013, from http://webspace.ship.edu/cgboer /personalityintroduction.html

Denzin, N.K., \& Lincoln, Y.S. (2003). Introduction: The discipline and practice of qualitative research. In N.K. Denzin \& Y.S Lincoln (Eds.), The landscape of qualitative research: theories and issues (pp.1-45). Thousand Oaks, CA: Sage.

Gaskell, G. (2000). .A practical Handbook. In M.W.Bauer \& G. Gaskell (Eds.). Qualitative researching with Text, Image and Sound. London: Sage

Gibbons, S. (2005). Library course-management system: An overview. ALA Library Technology Reports, 41(3), 7-11.

Krefting, L. (1991). Rigor in qualitative research: The assessment of trustworthiness. American Journal of Occupational Therapy, 45(3), 214222

McMillan, J.H., \& Wergin, J.F. (2002). Understanding and Evaluating Educational Research. Columbus: Merrill Prentice Hall.

McMillan, H. J., \& Schumacher, S. (2006). Research in Education: Evidence-Based Inquiry ( Ed.). New York: Pearson.

Mouton, J., \& Marais, H.C. (1994). Basic concepts in the methodology of the social sciences. Pretoria: Human Sciences Research Council.

Mouton, J. (2001). How to Succeed in Your Masters and Doctorial Studies: A South African Guide and Resource Book. Pretoria: Van Schaik Publishers.

Murphy, T.H., \& Lindner, J.R. (2001). Building and Supporting Online Learning Environments Through Web Course Tools: It Is Whippy, But Does It Work? Retrieved November 12, 2010 from http://agnews.tamu.edu/saas/Murphy.htm

Rogers, E.M. (2003). Diffusion of innovations. (5th ed.). New York: Free Press.

Rogers, E.M. (1995). Diffusion of innovations. (4th ed.). New York: Free Press.

Schmidt, K. (2002). The web-enhanced classroom. Journal of Information Technology, 18(2), 2-6.

Siemens, G. (2004). Connectivism: A learning Theory for the Digital Age. Retrieved January 12, 2014, from http://www.elearnspace.org IArticles/connectivism.htm

Ullman, C., \& Rabinowitz, M. (2004). Course management systems and the reinvention of instruction. Technological Horizons in Education Journal. Retrieved January 20, 2014, from http://thejournal.com/articles/17014.

Venkatesh, V. \& Davis, F.D. (2000). A theoretical extension of the technology acceptance model: Four longitudinal field studies. Management Science, 46(2), 186-204.

Venkatesh, V., Morris, M.G., Davis, G.B., \& Davis, F.D. (2003). User acceptance of information technology: Toward a unified view. MIS Quarterly, 27(3), 425-478. 